J. Dairy Sci. 101:5669-5669

https://doi.org/10.3168/jds.2018-101-6-5669

(c) American Dairy Science Association ${ }^{\circledR}, 2018$.

\title{
Corrigendum to "Technical note: An in vivo method to determine kinetics of unsaturated fatty acid biohydrogenation in the rumen" (J. Dairy Sci. 101:4259-4267)
}

\section{Baldin, D. E. Rico, M. H. Green, and K. J. Harvatine}

On page 4263, footnote 4 of Table 1 is incorrect. It should read "Calculated as (Post - Pre)/Pre." The complete table is shown below with the correction in bold.

The authors regret the error.

Table 1. Increase in concentration of oleic (OA), linoleic (LA), and $\alpha$-linolenic (ALA) acid in rumen digesta immediately following the bolus infusion ${ }^{1}$

\begin{tabular}{|c|c|c|c|c|c|}
\hline \multirow[b]{2}{*}{ Item } & \multirow{2}{*}{$\frac{\% \text { Rumen DM }}{\text { Total } \mathrm{FA}^{2}}$} & \multicolumn{4}{|c|}{$\%$ of Total FA $($ mean \pm SD $)$} \\
\hline & & $\mathrm{C} 17: 0$ & $\mathrm{OA}$ & LA & ALA \\
\hline Prebolus & $3.9 \pm 1.4$ & $0.4 \pm 0.1$ & $8.9 \pm 1.0$ & $11.1 \pm 1.8$ & $2.1 \pm 0.1$ \\
\hline Postbolus $^{3}$ & $7.3 \pm 1.4$ & $2.5 \pm 0.5$ & $30.1 \pm 4.6$ & $35.9 \pm 5.0$ & $19.8 \pm 4.3$ \\
\hline Fold-enrichment ${ }^{4}$ & $0.8 \pm 0.4$ & $5.1 \pm 0.9$ & $2.4 \pm 0.4$ & $2.2 \pm 0.2$ & $8.6 \pm 1.8$ \\
\hline
\end{tabular}

${ }^{1}$ Enrichment of total fatty acids (FA) and C17:0 pools were calculated within experiment and reported values represent an average across the 3 experiments. Enrichment of OA, LA, and ALA represent the geometric mean of 4 cows within each independent experiment.

${ }^{2}$ Total FA $(\% \mathrm{DM})$ before the bolus averaged $4.9( \pm 0.48), 3.42( \pm 0.33)$, and $3.06( \pm 0.36)$ for OA, LA, and ALA, respectively.

${ }^{3}$ Concentration of the first sample collected immediately after the bolus ( $\left.\sim 5 \mathrm{~min}\right)$.

${ }^{4}$ Calculated as (Post - Pre)/Pre.

\section{REFERENCES}

Baldin, M., D. E. Rico, M. H. Green, and K. J. Harvatine. 2018. Technical note: An in vivo method to determine kinetics of unsaturated fatty acid biohydrogenation in the rumen. J. Dairy Sci. 101(5):4259-4267. https://doi.org/10.3168/jds.2017-13452. 